\title{
The implementation of AIS and financial performance: empirical study in selected Jordanians banking institutions
}

\author{
Ali Mohammad Alsarayreh ${ }^{1 * *}$, Professor Dr. ALKA JAIN ${ }^{2}$, \\ Dr. Ahmad Hamed Al Manasir ${ }^{3}$ \\ ${ }^{1}$ Department of Studies in commerce, ISBR Research Centre Bangalore-University of \\ Mysore, Mysuru - 570006, INDIA. \\ ${ }^{2}$ Professor, Research department, ISBR Research Centre, Bangalore. \\ ${ }^{3}$ PhD. Accounting, Financial and administration Manager, Barzan Technology Solution, \\ Amman, Jordan.
}

\begin{abstract}
This article presents a reflection on the role of current Accounting Information Systems on financial performance in Jordanian banking sector. The study is based on primary data collected through a structured questionnaire. The data were analyzed using Multipleregression analysis.

The results indicated a significant impact of (SVQ) Service Quality, (IFQ) Information Quality, and (SYQ) System Quality on financial performance. Whilst showed no significant effect of (DQ) Data Quality on financial performance. The effectiveness of the accounting information system also improves the financial performance of banks. In light of the findings, this study suggests the management to establish better strategies that can ensure the effectiveness and efficacy of AIS.

The findings would be valuable for academic researchers, managers and professional accounting to acquire a better vision of the AIS by testing the phenomenon in Jordan as a developing country

This study is only conducted in Jordan as a developing country. Future research can be orientated to other national and cultural settings and compared with the results of this study.
\end{abstract}

Keywords: AIS, effectiveness, Jordanian banking sector, financial performance.

** Address of correspondence to this author; Tel: +962 792199012, E-mail: alisarayerh@yahoo.com 


\section{Introduction}

Information system for accounting IT includes AIS. It focuses on the recording, classification, summarization, and validation of data concerning financial transactions in businesses. These functions are carried out for the many groups within the organisation that are concerned with the financial accounting, managerial accounting, and tax compliance decisions (Hollander, Denna, \& Cherrington, 1999).

The accounting information system cannot be limited just to provide Data and information to external stakeholders such as banks creditors and government institution, the present time is the era of information revolution. Information has become no less important than financial and human resources in the conduct of business, building of organizations, and the conservation of resources available. Therefore, the provision of information is one of the critical areas that has received great attention as never before The rapid developments taking place in the contemporary world in the field of information revolution have reflected their effects on every sphere of life. With the great development that has taken place in the science of accounting, in particular the technological development and the emergence of computerized accounting systems, it has become necessary to pay more attention to accounting information systems because of their significant impact on the development of the science of accounting and related systems(Gizaw, Kebede, \& Selvaraj, 2015).

The expansion and practice of information technology innovations within the field of accounting, has produced a number of challenges to the traditional accounting system which necessitated for the pursuance of sustainable alternatives to be able to manage these challenges and hence, keep it competitive in line with international best practices (Alrabei, 2014). While the rapid and significant changes brought by the information technology affected the modern business environment, banking and other financial institutions are expected to be more abreast and elastic to such technological changes in order to operates within the global practices (Madhi, 2015).

Under the new technological advancement within the financial institutions, the use of Accounting Information System (AIS) in commercial banking activities indicate the strength and efficiency to provide the essential information required for performance appraisal and other policy decision-making. This vital information is regarded as an indispensable requirement for policy making in commercial banking operations as long as they possessed the good features of decision-making tools. In other words, the emergence as well as advent of accounting information systems and globalisation have mandated corporate organisations and business entities to adopt and utilised the AIS in order to survive and remain competitive (Abdelhak \& Dalel, 2009). Among financial institutions, banks are regarded among the most significant sectors that are affected by this development, and hence the need to transform to the use of accounting information systems which led to the improvement of the financial and administrative performance and the rapid expansion of decision making processes in the 
banking sector, as its provide tools which effectively enhance the process of decision making and performance evaluation.

Hence, there is a need for more practices of accounting information system in various financial institutions to allow the management of commercial banks to secure and maintain the global competitive advantage. However, the extent to which the increasing need for accounting information system will enhance the operational activities of commercial banks remain uncertain, since it provides an avenue on how to manage and enhance the operational services rendered to the clients, hence, evaluating organisational performance. A large number of financial institutions including the banking sector are yet to incorporate the accounting systems in daily operational activities, thus, this call for attention regarding some policy issues and performance of these institutions.

In view of that, this study is aimed at examining the effects of information system (hereafter Accounting Information System; AIS) on organizational performance of conventional commercial banks in Jordan under the contemporary technological advancement, with particular reference to measuring the proxy variable of AIS including information quality, system quality, data quality, and service quality. This study is aimed at evaluating the effectiveness of these information systems in terms of providing adequate and reliable information for decision-making in the complex world.

\subsection{Research Questions}

This study on the effects of AIS on the financial performance of commercial banks seeks to raise and identify the following research questions which may serve as a guide to the study: Main Question:

What is the impact of accounting information system (information quality, service quality, system quality, data quality) on financial performance of the commercial banks operating in Jordan?

\subsection{Objectives of the Study}

To analyse the effectiveness of AIS in enhancing the financial performance in selected commercial bank in Jordan.

\subsection{Hypotheses of the study}

1) Ha1: There is a statistically significant relationship between Accounting Information Systems (Service Quality) on Financial Performance of selected Jordanian Commercial Banks.

2) Ha2: There is a statistically significant relationship between Accounting Information Systems (Information Quality) on Financial Performance of selected Jordanian Commercial Banks. 
3) Ha3: There is a statistically significant relationship between Accounting Information Systems (System Quality) on Financial Performance of selected Jordanian Commercial Banks.

4) Ha4: There is a statistically significant relationship between Accounting Information Systems (Data Quality) on Financial Performance of selected Jordanian Commercial Banks.

5) Ha5: The applied accounting information system in the banks achieves the required effectiveness.

\subsection{Scope of the Study}

This research is centred on the relationship between data quality, information quality, system quality, and service quality as proxies of AIS and financial performance among selected Jordanian commercial banks. The boundary of this study is within the financial institutions of Jordan, with particular reference to the selected Jordanian commercial banks. This is because the banking sector is the most matured and organised sector compared to other sectors of Jordan economy (JBS, 2015). Banks are generally grouped as central banks, commercial, foreign banks and specialised banks. The specialised banks include industrial, agricultural, cooperative, real estate, and saving deposit banks (CBJ, 2020). Precisely, this study focuses on the selected Jordanian commercial banks due to its functional relationship with information system and the contribution to national economy.

\section{THE RELATIONSHIP BETWEEN ACCOUNTING INFORMATION SYSTEM (AIS) AND ORGANIZATIONAL PERFORMANCE}

One of the most crucial systems in any firm is the accounting information system. Its goal is to equip managers at all levels with the information they require. This information aids them in carrying out their planning, resource monitoring, performance evaluation, and decisionmaking responsibilities successfully and efficiently (Saeidi \& Prasad, 2014). Esmeray (2016) also did research to see how accounting information systems affect the financial performance of small and medium-sized firms in Turkey. The analytical descriptive strategy was used to attain the study's goal by producing a questionnaire and disseminating it to the study sample, which consisted of 60 enterprises in the city of Qaisariya. The study's findings revealed a statistically significant beneficial association between the adoption of accounting information systems and sales, refunds, and customer number increase.

Accounting information systems have been widely implemented by both public and private sector enterprises (Rom \& Rohde, 2007). For decision-making, managerial control, and performance management, firms use an accounting information system that includes both structured and unstructured financial and non-financial data (Granlund, 2011).

Some researchers (Tayeh, Al-Jarrah, \& Tarhini, 2015) argued that since the Accounting Information System (AIS) has been an important concern to the business community (Abbasi, Tarhini, Elyas, \& Shah, 2015; Masa'deh, 2013), as it is not only helps firms recognize the 
potential benefits from investments in IT (Alkalha, Al-Zu'bi, Al-Dmour, Alshurideh, \& Masa'deh, 2012; Altamony, Alshurideh, \& Obeidat, 2012), but also improves business performance (Abu-Shanab, Abu-Shehab, \& Khairallah, 2015). However, it is known that no single measure of performance could fully account for all aspects of firm performance (Ibrahim, Zolait, \& Sundram, 2010). Moreover, although firm performance has been assessed using a diversity of measures, there is no universal guideline regarding the appropriate choice. Researchers measure performance objectively and/or subjectively, where objective measurements depend upon profit and financial data, and subjective measurements rely on managerial assessments.

Emad et al. (2014) investigated the impact of accounting information systems on the performance of small and medium-sized businesses in Iraq. This study used a theoretical analytical method to arrive at its conclusions, which included evaluating prior studies, the notion of accounting information systems, and the nature of small and medium-sized company performance. The findings revealed that the characteristics of accounting information systems (reliability, importance, and timing) had an impact on the performance of small and medium-sized businesses in Iraq. Previous studies found positive relationship between AIS and performance like (Ali, Omar, \& Bakar, 2016; Arabmazar Yazdi, Nasseri, Nekoee Zadeh, \& Moradi, 2017; Budiarto, Prabowo, Djajanto, Widodo, \& Herawan, 2018; Grande, Estébanez, \& Colomina, 2011; Soudani, 2012; Urquía Grande, Pérez Estébanez, \& Muñoz Colomina, 2011).

\section{Research method}

This study uses a quantitative research method, which is the most suited research methodology. The quantitative technique entails a system of investigating clarity through the relationship between several variables, which may be reduced to numerical data and potentially extrapolated to larger populations (Kumar, 2019).

In this research, a survey will be used as a research design. The branch managers or assistant branch managers of the selected conventional commercial banks in Jordan are the study's target group. As a result, a total of eight (8) commercial banks were enlisted, and a set of questionnaires were made available and delivered to these banks' branches. The justification for chosen the branch managers or assistant branch managers is affirmed by their designated official functions whom are believed to have the superior advantage in responding appropriately to the questionnaires (Badawy, 2015).

Table 4.1 below shows the number of branches in each of the eight selected commercial banks to be investigated by this study, and therefore are presented as follows. 
Table 4.1: Population of selected Jordanian Commercial Banks

\begin{tabular}{|l|l|c|}
\hline S/N & Name of Bank & $\begin{array}{l}\text { No. of } \\
\text { Branches: }\end{array}$ \\
\hline 1 & Arab Bank (ARBK) & 185 \\
\hline 2 & Arab Banking Corporation (ABCO) & 26 \\
\hline 3 & Arab Jordan Investment Bank (AJIB) & 11 \\
\hline 4 & Bank of Jordan (BOJX) & 94 \\
\hline 5 & Cairo Amman Bank (CABK) & 93 \\
\hline 6 & Capital Bank of Jordan (EXFB) & 12 \\
\hline 7 & Jordan Ahli Bank (AHLI) & 67 \\
\hline 8 & Jordan Kuwait Bank (JOKB) & 56 \\
\hline & Total & $\mathbf{5 4 4}$ \\
\hline
\end{tabular}

Source: (CBJ, 2020)

The total number of selected Jordanian conventional commercial banks branches is 544 . On the basis of this population, the sample size is computed, and the sampling is done. If the entire population is 544, a total sample size of 226 is valid, according to Sekaran and Bougie (2010). As a result, a sample of 226 respondents is sufficient for a population of 544 respondents in this study. A total of 363 questionnaires will be disseminated across all of the selected commercial banks to allow for data filtering and cleaning, non-response rate, and other data collection omissions.

The questionnaires will collect by using an on-line survey approach where the researcher provided the questionnaire to the respondents by email. The benefits of online surveys are vast. In fact, (Wiersma, 2013) noted that online surveys are one of the cheapest, most convenient means of data collection that include very limited influence from social bias. Even though creating an online survey nowadays is much easier than in the past, that's not to say all aspects of surveys are easy specifically during COVID-19. The following benefits can be gained: (1) Cost-Effective; (2) Ease of gathering data; (3) Can be sent to many people in a few clicks; (4) Respondents have their own time to respond; and (5) Honest answers from the respondents.

\section{DATA ANALYSIS AND HYPOTHESES TESTING}

The researcher has used the program of Statistical Package for Social Science (SPSS), version 26. Descriptive statistics, psychometric analysis of the measurement scales that are employed in the study namely, Cronbach's Alpha Reliability Test, pearson correlation , regression analysis, and hypothesis testing.

\subsection{Response Rate}

Based on the research design, the objective of this study is to distribute a questionnaire to 363 branch managers or assistant branch managers of chosen Jordanian conventional commercial banks; 273 questionnaires were returned, reflecting a 75 percent response rate. Obtaining the 
required response rate necessitates ongoing contact with the bank's secretary via phone calls and SMS to facilitate the return of questionnaires that are still in the custody of some respondents after three weeks.

\subsection{Multicollinearity Test}

The degree to which a variable can be explained by other variables in the analysis is determined by the correlation between the study's latent independent variables (Hair et al., 2010a). Pallant (2010) defined multicollinearity as "the interaction between independent variables. Multicollinearity, on the other hand, occurs when one unobserved latent independent construct and others have a strong association (Hair et al., 2010). The value equal to and greater than $90 \%(r \geq 0.9)$ means that there is multicollinearity among the independent variables (Pallant, 2010).

The table depicts the correlation matrix for the dependent, explanatory variables used for model. Nevertheless, the magnitude of both the Pearson correlation coefficients (parametric) and Spearman correlation coefficients (non-parametric) seems to be comparatively similar. This added to the proof that there are no main problems of non-normality amongst the variables in the models. Additionally, both report that the correlations amongst the variables are fairly low, indicate that there is not a serious multicollinearity problem.

Table 5.4: Inter-Constructs Correlations for Multicollinearity Test

\section{Correlations}

\begin{tabular}{|c|c|c|c|c|c|c|}
\hline & FP & SVQ & IFQ & SEQ & DQ & $\mathrm{EFC}$ \\
\hline FP & 1 & $.636^{* * *}$ & $.631^{* * *}$ & $.560^{* * *}$ & $.432^{* *}$ & $.625^{* *}$ \\
\hline SVQ & $.639^{* *}$ & 1 & $.756^{* *}$ & $.621^{\text {** }}$ & $.597^{* *}$ & $.404^{* * *}$ \\
\hline IFQ & $.638^{* *}$ & $.737^{* *}$ & 1 & $.740^{* * *}$ & $.647^{* *}$ & $.353^{* * *}$ \\
\hline SEQ & $.563^{* *}$ & $.580^{* *}$ & $.716^{* * *}$ & 1 & $.621^{* * *}$ & $.342^{* * *}$ \\
\hline DQ & $.426^{* *}$ & $.559^{* *}$ & $.655^{* *}$ & $.619^{\text {** }}$ & 1 & $.274^{* * *}$ \\
\hline EFC & $.650^{* *}$ & $.435^{* * *}$ & $.381^{* * *}$ & $.378^{* *}$ & $.292 * *$ & 1 \\
\hline
\end{tabular}

**. Correlation is significant at the 0.01 level (2-tailed).

Notes: The bottom left half of the table contains, Spearman's non-parametric correlation coefficients. Whereas the upper right half of the table shows Pearson's parametric correlation coefficients. ${ }^{* *}$, and ${ }^{*}$ indicate significance at $1 \%$ and $5 \%$ levels.

\subsection{Testing for Normality}

Normality was tested to check if the variables are normally-distributed this research scrutinised the normality of data by employing Skewness and Kurtosis tests corroborate the result of fairly normal distribution of majority of the variables. Specially, the normal distribution of the Financial Performance was examined by utilising Skewness and Kurtosis tests. According to (Sekaran \& R. Bougie, 2016), normality is assumed when the ratio of Skewness and standard error and the ratio of Kurtosis and standard error fall between $+/-$ 1.96, at the alpha of 0.05 , and $+/-2.58$, at the alpha of 0.01 . As indicated in the Appendix 2-1, 
both ratios of skewness/standard error and kurtosis/standard error fall in the rule of thumb. Based on the cut off, the normality is met.

Table 5.6: Test of Normality

\begin{tabular}{|c|c|c|}
\hline $\begin{array}{l}\grave{\vdots} \\
\vdots \\
\frac{\tilde{\sigma}}{\sigma}\end{array}$ & 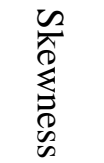 & 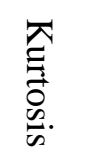 \\
\hline FP & -.336 & .311 \\
\hline SVQ & -.531 & .345 \\
\hline IFQ & -.354 & .251 \\
\hline SEQ & -.427 & .517 \\
\hline DQ & -.670 & .410 \\
\hline $\mathrm{EFC}$ & -.337 & .255 \\
\hline
\end{tabular}

\subsection{Reliability Analysis}

According to U. Sekaran and R. Bougie (2016), reliability test is used for the measurement of the variables consistency and stability, with the main tool for the test being the Cronbach's alpha. A Cronbach's alpha coefficient that is near to 1.00 shows better data reliability. Moreover, there are different reports about the acceptable values of alpha, ranging from 0.60 to 0.95 . If the value of $\alpha$ is greater than or equal to 0.6 but less than 0.7 is considered acceptable. Besides, the value of $\alpha$ greater than or equal to 0.7 but less than 0.9 is considered good and the value of $\alpha$ greater than or equal to 0.9 is considered excellent (Nunnally, 1994).

As indicated in Table 5-15, an assessment of dimensions of accounting information systems (AIS), effectiveness of (AIS) is conducted. Dimension of SVQ has 8 items, dimensions of IFQ has 15 items, dimension of SYQ has 14 items, dimension of DQ has 6 items, effectiveness of (AIS) has 5-items, and the dependent variable FP has 9 items. The reliability alpha assessment generates the accepted reliability score with coefficient of $0.88,0.91,0.93$, $0.87,0.82$, and .849 , respectively. In addition, the item deletion does not result in significant increase in alpha coefficient score, indicating stable internal consistent scales (Nunnally, 1994).

Table 5.15 : The stability of the instrument Cronbach's alpha

\begin{tabular}{|c|l|c|c|c|}
\hline NO & \multicolumn{1}{|c|}{ Scale Item } & No of items & Cronbach's Alpha & Remarks \\
\hline 1 & SVQ & 8 & .881 & good \\
\hline 2 & IFQ & 15 & .917 & excellent \\
\hline 3 & SYQ & 14 & .935 & excellent \\
\hline 4 & DQ & 6 & .875 & good \\
\hline 5 & EFC & 5 & .818 & good \\
\hline 6 & FP & 9 & .849 & good \\
\hline
\end{tabular}




\subsection{Testing of Hypothesis}

\subsubsection{The Multiple Regression model}

Multiple-regression analysis combines more than one explanatory-variable to identify the effects of those variables on the dependent-variable (Gujarati, 2008). This kind of analysis is likewise a form of general linear modelling (Hair, 2010). Multiple-regression analysis was utilized to scrutinise the effect of (independent variables) on (dependent variables).

Where: $F P=$ financial performance, $a=$ Constant (Intercept), SVQ = Service Quality, IFQ = Information Quality, SYQ = System Quality, DQ= Data Quality, EFC= Effectiveness and e = Error term.

$$
\mathrm{FP}=\mathbf{a}+\beta 1 \mathrm{SVQ}+\beta 2 \mathrm{IFQ}+\beta 3 \mathrm{SYQ}+\beta 4 \mathrm{DQ}+\beta 5 \mathrm{EFC}+\mathrm{e}
$$

4.5.2 The Relationship Between Each Dimension of (AIS), effectiveness of (AIS) and Financial Performance FP

Multiple Regression Analysis has used to investigate the relationship. This model was used to test the Sub Hypothesis. The main empirical results are reported in Tables $(5.24,25,26,27)$. The model is significant at level of 0.01 with an $\mathrm{R}^{2}$ of $61.5 \%$.

Table 5.27 Multiple Regression Analysis Results

\begin{tabular}{|l|l|}
\hline Independent Variables & \multicolumn{1}{|c|}{$\begin{array}{c}\text { Dependent Variable } \\
\text { Financial Performance (FP) }\end{array}$} \\
\hline Service Quality & $.220^{* * *}$ \\
\hline Information Quality & 3.808 \\
\hline & $.265^{* * *}$ \\
\hline System Quality & 3.615 \\
\hline & $.109 * *$ \\
\hline Data Quality & 1.963 \\
\hline & -.053 \\
\hline Effectiveness & -1.214 \\
\hline & $.393 * * *$ \\
\hline Observations & 9.67 \\
\hline R-Squared & 261 \\
\hline F-Statistic & .615 \\
\hline P-Value & 80.908 \\
\hline
\end{tabular}

Robust t-statistics are reported in parentheses

** Indicate statistically significant at the 5\% level.

*** Indicate statistically significant at the $1 \%$ level 
To achieve the objectives of the study, the following hypotheses have been developed for statistical testing:

\section{Hypothesis 1}

1) Ha1: There is a statistically significant relationship between Accounting Information Systems (Service Quality) on Financial Performance of selected Jordanian Commercial Banks.

Table 5.27 shows the values of regression coefficients of Service Quality and Financial Performance. An unstandardized beta coefficient gives a measure of contribution of each variable to the model. A larger value indicates that a unit change in the predictor variable has a larger impact on the criterion variable. The results show that Service Quality has positive impact on Financial Performance since the unstandardized beta coefficient is 0.220 . It indicates that for every one unit change in Service Quality, there will be 0.220 unit change in Financial Performance. However, its regression coefficient is statistically significant at $1 \%$ level of significance $(\mathrm{P}<0.01)$. Therefore, the null hypothesis is rejected and it can be said that there is a significant relationship between Accounting Information Systems (Service Quality) on Financial Performance of selected Jordanian Commercial Banks.

\section{Hypothesis 2}

2) Ha2: There is a statistically significant relationship between Accounting Information Systems (Information Quality) on Financial Performance of selected Jordanian Commercial Banks.

Table 5.27 shows the values of regression coefficients of Information Quality and Financial Performance. An unstandardized beta coefficient gives a measure of contribution of each variable to the model. A larger value indicates that a unit change in the predictor variable has a larger impact on the criterion variable. The results show that Information Quality has positive impact on Financial Performance since the unstandardized beta coefficient is 0.265. It indicates that for every one unit change in Information Quality, there will be 0.447 unit change in Financial Performance. However, its regression coefficient is statistically significant at $1 \%$ level of significance $(\mathrm{P}<0.01)$. Therefore, the null hypothesis is rejected and it can be said that there is a significant relationship between Accounting Information Systems (Information Quality) on Financial Performance of selected Jordanian Commercial Banks.

\section{Hypothesis 3}

3) Ha3: There is a statistically significant relationship between Accounting Information Systems (System Quality) on Financial Performance of selected Jordanian Commercial Banks.

Table 5.27 shows the values of regression coefficients of System Quality and Financial Performance. An unstandardized beta coefficient gives a measure of contribution of each variable to the model. A larger value indicates that a unit change in the predictor variable has a larger impact on the criterion variable. The results show that System Quality has positive 
impact on Financial Performance since the unstandardized beta coefficient is 0.109. It indicates that for every one unit change in System Quality, there will be 0.109 unit change in Financial Performance. However, its regression coefficient is statistically significant at 5\% level of significance $(\mathrm{P}<0.05)$. Therefore, the null hypothesis is rejected and it can be said that there is a significant relationship between Accounting Information Systems (System Quality) on Financial Performance of selected Jordanian Commercial Banks.

\section{Hypothesis 4}

4) Ha4: There is a statistically significant relationship between Accounting Information Systems (Data Quality) on Financial Performance of selected Jordanian Commercial Banks.

Table 5.27 shows the values of regression coefficients of Data Quality and Financial Performance. An unstandardized beta coefficient gives a measure of contribution of each variable to the model. A larger value indicates that a unit change in the predictor variable has a larger impact on the criterion variable. The results show that Data Quality has negative impact on Financial Performance since the unstandardized beta coefficient is -.053. It indicates that for every one unit change in quality information, there will be 0.049 unit change in market share. However, its regression coefficient is statistically insignificant at $5 \%$ level of significance $(\mathrm{P}>0.05)$. Therefore, the null hypothesis is accepted and it can be said that there is no statistically significant relationship between Accounting Information Systems (Data Quality) on Financial Performance of selected Jordanian Commercial Banks.

\section{Hypothesis 5}

\section{5) Ha5: The applied accounting information system in the banks achieves the required} effectiveness..

By taking a look at the table No (5.27) it appears that the value of calculated $T$ is (9.670), which is higher than tabulated T value. Since the decision rule is: reject null hypothesis if the calculated value is higher than the tabulated value, and accept it if the calculated value is greater than the tabulated value. Add to that, the significance level value is lower than 0.05 which is 0.00 and as the decision rule said that, reject the null hypothesis if significance level value is greater than significance level value adopted, and accept the null hypothesis if the significance level value is lower than the significance level value adopted. We therefore, reject the null hypothesis (Ho5) and accept the alternative hypothesis ( $\mathrm{H}_{\mathrm{a}}$ ). This means that "The applied accounting information system in the banks achieves the required effectiveness ".

The hypothesis testing resulting from the regression analysis as explained in the previous section could be summarized in Tables 5.28 
Table 5.28: Summary of Hypothesis Tested

\begin{tabular}{|c|l|c|c|}
\hline No. & \multicolumn{1}{|c|}{ Hypotheses } & Results \\
\hline 1 & $\begin{array}{l}\text { There is no statistically significant relationship between Accounting } \\
\text { Information Systems (Service Quality) on Financial Performance of selected } \\
\text { Jordanian Commercial Banks. }\end{array}$ & Rejected \\
\hline 2 & $\begin{array}{l}\text { There is no statistically significant relationship between Accounting } \\
\text { Information Systems (Information Quality) on Financial Performance of } \\
\text { selected Jordanian Commercial Banks. }\end{array}$ & Rejected \\
\hline 3 & $\begin{array}{l}\text { There is no statistically significant relationship between Accounting } \\
\text { Information Systems (System Quality) on Financial Performance of selected } \\
\text { Jordanian Commercial Banks. }\end{array}$ & Rejected \\
\hline 4 & $\begin{array}{l}\text { There is no statistically significant relationship between Accounting } \\
\text { Information Systems (Data Quality) on Financial Performance of selected } \\
\text { Jordanian Commercial Banks. }\end{array}$ & Accepted \\
\hline 5 & $\begin{array}{l}\text { The applied accounting information system in the banks does not achieve the } \\
\text { required effectiveness. }\end{array}$ & Rejected \\
\hline
\end{tabular}

\section{CONCLUSION AND SUGGESTIONS}

This study is intended to shed light on the assessment of computerized accounting information systems in selected Jordanian Commercial Banks. The researcher concludes that according to the findings of the study the efficiency and effectiveness required in the banks operating in Jordan are applied. Since, all the users of accounting financial reporting are satisfied. Furthermore, the accounting information system is accuracy, highly secured, up to date, suitable to all users, covers all the needs, facilitate the ability of exchanging data between all departments, less errors, and decreasing overall cost. In addition, the cost of accounting system is reasonable and entering data, processing and preparing reports are been more easy and more speedy which can save time and cost. As results of efficiency and effectiveness of accounting information system, the quality of outputs is improved.

Depending on the theoretical part of the study and the conclusion of the study it was an important to add some recommendations which can help in developing the accounting information system in any organizations in the future in order to cover the gaps of using and understanding the accounting information system.

1- To continue modernization of the accounting system in full not partial in the working banks in the Jordan.

2- To continue Staff development of electronic systems in the working banks.

3- To continue adoption of the educated and skilled employees on accounting information system.

4- Activation of the government authorities in controlling and supervision of the effectiveness and efficiency of accounting information system. 
The findings of this study are based on a single industry (banking industry). As a result, it might be difficult to generalize the findings to organizations in other industries without carrying out a similar study on them.

Second, the empirical evaluation and assessment begins in Feb of the year 2021 during COVID-19 pandemic. Regardless of numerous efforts to increase the number of responses, the study was finally able to collect 273 responses from a sample of 363 from branch managers or assistant branch managers.

In line with the limitations of this study, the current study is based on a sample size taken from eight banks in Jordan. Therefore, the results cannot be generalized to other industries of Jordan especially in the analytical terms, future researchers could conduct a similar study in other financial institutions in Jordan like the Islamic Banks, Foreign banks, etc. with a view to corroborating the findings of this study.

\section{REFERENCES}

Abbasi, M. S., Tarhini, A., Elyas, T., \& Shah, F. (2015). Impact of individualism and collectivism over the individual's technology acceptance behaviour: A multi-group analysis between Pakistan and Turkey. Journal of Enterprise Information Management, 28(6), 747-768.

Abdelhak, D., \& Dalel, H. (2009). Computerized information systems in the Jordanian banking sector: An empirical study. Laboratoire finances, banques et management, 3 17.

Abu-Shanab, E., Abu-Shehab, R., \& Khairallah, M. (2015). Critical success factors for ERP implementation: The case of Jordan. The International Arab Journal of e-Technology, 4(1), 1-7.

Ali, B., Omar, W. A. W., \& Bakar, R. (2016). Accounting Information System (AIS) and organizational performance: Moderating effect of organizational culture. International Journal of Economics, Commerce and Management, 4(4), 138-158.

Alkalha, Z., Al-Zu'bi, Z., Al-Dmour, H., Alshurideh, M., \& Masa'deh, R. (2012). Investigating the effects of human resource policies on organizational performance: An empirical study on commercial banks operating in Jordan. European Journal of Economics, Finance and Administrative Sciences, 51(1), 44-64.

Alrabei, A. M. A. (2014). The impact of accounting information system on the Islamic Banks of Jordan: an empirical study. European Scientific Journal, 10(4).

Altamony, H., Alshurideh, M., \& Obeidat, B. (2012). Information systems for competitive advantage: Implementation of an organisational strategic management process. Paper presented at the Proceedings of the 18th IBIMA conference on innovation and sustainable economic competitive advantage: From regional development to world economic, Istanbul, Turkey, 9th-10th May. 
Arabmazar Yazdi, M., Nasseri, A., Nekoee Zadeh, M., \& Moradi, A. (2017). The Impact of Accounting Information System Flexibility on Firm Performance with Dynamic Capabilities Approach. Journal of Accounting and Auditing Review, 24(2), 221-242.

Badawy, H. A. E. S. M. (2015). The Effect of External Assurance on RTA Information System on System Users' Reliance Experimental Study.

Budiarto, D. S., Prabowo, M. A., Djajanto, L., Widodo, K. P., \& Herawan, T. (2018). Accounting information system (ais) alignment and non-financial performance in small firm: a contingency perspective. Paper presented at the International Conference on Computational Science and Its Applications.

CBJ. (2020). Annual Report.

Gizaw, M., Kebede, M., \& Selvaraj, S. (2015). The impact of credit risk on profitability performance of commercial banks in Ethiopia. African Journal of Business Management, 9(2), 59-66.

Grande, E. U., Estébanez, R. P., \& Colomina, C. M. (2011). The impact of Accounting Information Systems (AIS) on performance measures: empirical evidence in Spanish SMEs. The international journal of digital accounting research, 11(1577-8517), 25 43.

Granlund, M. (2011). Extending AIS research to management accounting and control issues: A research note. International Journal of Accounting Information Systems, 12(1), 3 19.

Hollander, A., Denna, E., \& Cherrington, J. O. (1999). Accounting, information technology, and business solutions: McGraw-Hill Higher Education.

Ibrahim, A. R., Zolait, A. H., \& Sundram, V. P. (2010). Supply chain management practices and firm performance: An empirical study of the electronics industry in Malaysia. International Journal of Technology Diffusion (IJTD), 1(3), 48-55.

JBS. (2015).

Madhi, E. (2015). A SURVEY OF THE ACCOUNTING INFORMATION SYSTEMS USED BY THE BANKING INDUSTRY IN ALBANIA. Journal of Information Systems \& Operations Management, 9(2).

Masa'deh, R. e. M. (2013). The impact of information technology infrastructure flexibility on firm performance: An empirical study of Jordanian public shareholding firms. Jordan Journal of Business Administration, 153(954), 1-42.

Nunnally, J. C. (1994). The assessment of reliability. Psychometric theory.

Pallant, J. (2010). SPSS Survival manual: a step by step guide to data analysis using SPSS. Berkshire UK: McGraw-Hill Education, (4th ed.). New York: Open University Press.

Sekaran, \& Bougie, R. (2016). Research methods for business: A skill building approach: John Wiley \& Sons.

Sekaran, U., \& Bougie, R. (2016). Research methods for business: A skill building approach: John Wiley \& Sons.

Soudani, S. N. (2012). The Usefulness of an Accounting Information System for Effective Organizational Performance. International Journal of Economics and Finance, 4(5), 136-145. doi:10.5539/ijef.v4n5p136 
Tayeh, M., Al-Jarrah, I. M., \& Tarhini, A. (2015). Accounting vs. market-based measures of firm performance related to information technology investments. International Review of Social Sciences and Humanities, 9(1), 129-145.

Urquía Grande, E., Pérez Estébanez, R., \& Muñoz Colomina, C. (2011). The impact of Accounting Information Systems (AIS) on performance measures: empirical evidence in Spanish SMEs.

Wiersma, W. (2013). The validity of surveys: Online and offline. Oxford Internet Institute, $18(3), 321-340$. 